\section{IQ and Race}

JENSEN has argued that the undoubted differences in mean IQ scores between racial groups in the United States reflect differences in genetic endowment. But a major problem in the interpretation of these differences is the difficulty of studying environmental and genetic effects separately. Each race tends to have, for historical reasons, characteristic childrearing practices which are to some extent independent of social class. Hence the argument that because black children tend to have lower IQs than white children of the same social class they are genetically inferior is unconvincing; the inferior test scores could result from differences in the microenvironment of the family, such as linguistic practices and attitudes to achievement.

My colleagues and I have recently had an opportunity to study children of different racial origins reared in an identical environment. These were illegitimate children admitted to residential nurseries as infants until such time as their mothers could look after them or they could be found adoptive homes. All those tested had been healthy, full-term babies: the residential nurseries, run by three voluntary societies, were in sixty-four such children: twenty-five were still in institutions, twenty-four had been adopted into white families at a mean age of $3.1 \mathrm{yr}$, and fifteen had been restored to their mothers (all but one of whom were white) at a mean age of $3.5 \mathrm{yr}^{2}$. Table 2 shows that the mean IQs of the different racial groups in each environment were very similar.

These studies were not undertaken with the aim of comparing the scores of different racial groups, but rather to examine the effects of different environments on development. In the first study children in nurseries where the quality of the staff talk to children (as assessed in observations) was highest had mean language comprehension scores one and a half standard deviations above those of children in the nurseries where the quality of staff talk was lowest. In the second study the adopted children had significantly higher mean IQs than either the children still in nurseries or those restored to their mothers, and these differences were related to measured aspects of the children's environment.

In both studies genetic aspects were neither controlled nor adequately known, that is, the children had not been randomly assigned to different environments and no parental IQs were available. It could therefore be argued that the

Table 1 Test Scores of Eighty-five Residential Nursery Children

\begin{tabular}{|c|c|c|c|c|c|c|c|c|c|}
\hline & \multicolumn{3}{|c|}{ Reynell comprehension* } & \multicolumn{3}{|c|}{ Reynell expression* } & \multicolumn{3}{|c|}{ Minnesota non-verbal $\dagger$} \\
\hline & $N$ & Mean & s.d. & $N$ & Mean & s.d. & $N$ & Mean & s.d. \\
\hline White children & 39 & 102.6 & 10.0 & 39 & 98.5 & 11.2 & 24 & 101.3 & 11.1 \\
\hline Black children + & 22 & 106.9 & 8.7 & 22 & 97.8 & 8.5 & 15 & 105.7 & 7.4 \\
\hline Mixed race children§ & 24 & 105.7 & 10.2 & 24 & 99.3 & 8.7 & 15 & 109.8 & 7.2 \\
\hline White against non-white & \multicolumn{3}{|c|}{$\mathrm{t}=1.70$, n.s. } & \multicolumn{3}{|c|}{$\mathrm{t}=0.02$, n.s. } & \multicolumn{3}{|c|}{$\mathrm{t}=2.51, P<0.02$} \\
\hline
\end{tabular}

* Converted to a mean of 100 , s.d. 10.

$\dagger$ Only given to children aged $3 \mathrm{yr}$ and older.

$\ddagger$ Children with two West Indian or African parents.

$\S$ Children with one West Indian or African parent and one white parent.

Table 2 Wechsler Pre-school and Primary Scale of Intelligence Full Scale IQs of Sixty-four Children Aged 4.5 yr

\begin{tabular}{|c|c|c|c|c|c|c|c|c|c|}
\hline & \multicolumn{3}{|c|}{ Institutional } & \multicolumn{3}{|c|}{ Adopted } & \multicolumn{3}{|c|}{ Restored to mother } \\
\hline & $N$ & Mean & s.d. & $N$ & Mean & s.d. & $N$ & Mean & s.d. \\
\hline White children & 10 & 101.2 & 10.7 & 17 & 113.0 & 7.8 & 9 & 98.2 & 10.8 \\
\hline Mixed race children & 7 & 109.3 & 8.2 & 7 & 119.9 & 16.6 & 5 & 102.2 & 12.3 \\
\hline Black children & 8 & 105.6 & 10.3 & 0 & & & 1 & 106.0 & \\
\hline White against non-white & & $t=1.55$, n.s. & & & $t=1.45, \mathrm{n}$ & & & $t=0.80$, & \\
\hline
\end{tabular}

many respects of high quality, with a generous staff-child ratio and a plentiful supply of toys and books. Because the nurseries tended to be isolated the children did not meet community colour prejudice, and within the nurseries we saw no sign of such prejudice.

In the first study we tested all the healthy children in thirteen residential nursery groups who had been there at least six months and who were aged 2 yr 0 month- 4 yr 11 months. Thirty-nine children had two white parents, twentytwo had two West Indian or African parents, and twenty-four were racially mixed. Seventy per cent had been admitted before their first birthday, and $86 \%$ before their second ${ }^{1}$. The children were tested with a non-verbal intelligence test and a test of language comprehension and expression. Table 1 shows that the mean test scores of the different racial groups were very similar, and the only significant difference was in favour of the non-white children.

In the second study we tested all the available children aged $4.5 \mathrm{yr}$ who had been admitted to any of the residential nurseries of these voluntary societies by the age of 4 months and remained there until at least the age of $2 \mathrm{yr}$. We found non-white parents may have been of higher IQ than the white parents, or that children of higher IQ parents had been adopted or placed in nurseries where the staff talk was of high quality. We found no evidence to support such hypotheses. Children were placed in whichever nursery had a vacancy, and no attempt was made to assess the IQ of the children or their natural parents before placing them for adoption. The occupation of a third of the natural fathers was unknown, but for the rest there was no significant difference between the proportions of manual and nonmanual workers in the different racial groups or different home or nursery environments. On the other hand, in both studies the relationship between the children's test scores and measured aspects of the environment was shown to be large and significant.

Senior Barnardo Research Fellow,

Barbara Tizard

\section{Institute of Education}

1 Tizard, B., Cooperman, O., Joseph, A., and Tizard, J., Child Dev., 43, 337 (1972).

2 Tizard, B., and Rees, J., Child Dev. (in the press). 